\title{
Erratum to: Disentangling Multiple Sclerosis and depression: an adjusted depression screening score for patient-centered care
}

\author{
Douglas D. Gunzler ${ }^{1} \cdot$ Adam Perzynski $^{1} \cdot$ Nathan Morris $^{2} \cdot$ Robert Bermel $^{3}$. \\ Steven Lewis ${ }^{1} \cdot$ Deborah Miller $^{3}$
}

Published online: September 28, 2015

(c) Springer Science+Business Media New York 2015

\section{Erratum to: J Behav Med (2015) 38:237-250 DOI:10.1007/s10865-014-9574-5}

The Publisher of the Journal of Behavioral Medicine and the authors of "Disentangling Multiple Sclerosis and Depression: An Adjusted Depression Screening Score for Patient-Centered Care" (Douglas D. Gunzler, Adam Perzynski, Nathan Morris, Robert Bermel, Steven Lewis \& Deborah Miller), published in Volume 38:2, pages 237-250, have come to learn of a registered copyright of

The online version of the original article can be found under doi:10. 1007/s10865-014-9574-5.

\section{Douglas D. Gunzler}

dgunzler@metrohealth.org

Adam Perzynski

atp5@case.edu

Nathan Morris

njm18@case.edu

Robert Bermel

BERMELR@ccf.org

Steven Lewis

sal25@case.edu

Deborah Miller

MILLERD@ccf.org

1 Center for Health Care Research and Policy, MetroHealth Medical Center, Case Western Reserve University, 2500 MetroHealth Drive, Cleveland, OH 44109-1998, USA

2 Department of Epidemiology and Biostatistics, Case Western Reserve University, 10900 Euclid Ave., Cleveland, OH 44106-4945, USA

3 Mellen Center for Multiple Sclerosis Treatment and Research, Cleveland Clinic Main Campus, Mail Code U10, 9500 Euclid Avenue, Cleveland, OH 44195, USA the Performance Scales $₫$. See Performance Scales, Copyright Registration Number/Date: TXu000743629/1996-0404; assigned to DeltaQuest Foundation, Inc., effective October 1, 2005. U.S. Copyright law governs terms of use. The authors failed to report that Performance Scales $\subseteq$ is a copyrighted work and is owned by DeltaQuest Foundation. The Performance Scales $($ is a copyrighted work of DeltaQuest Foundation, Inc. that can only be used, amended, adapted, translated, made into a derivative work or published with the explicit permission of and license from DeltaQuest Foundation, Inc. Further, the "Performance Scales@ (PS)" has been incorrectly referred to as the "performance scales" or "MS-related fatigue, cognitive, mobility and hand function domains with six ordinal responses" throughout the paper. Additionally, the article referenced the original validation paper second rather than first, leading to some confusion as to the authorship of the original validation study which should be Schwartz, C.E., Vollmer, T., and Lee, H. (1999), Reliability and validity of two self-report measures of impairment and disability for MS. Neurology, 52, 63-70, and of the copyrighted work. To address the issue, we are providing this erratum and wish to express our regret for the oversight that resulted in these errors. 